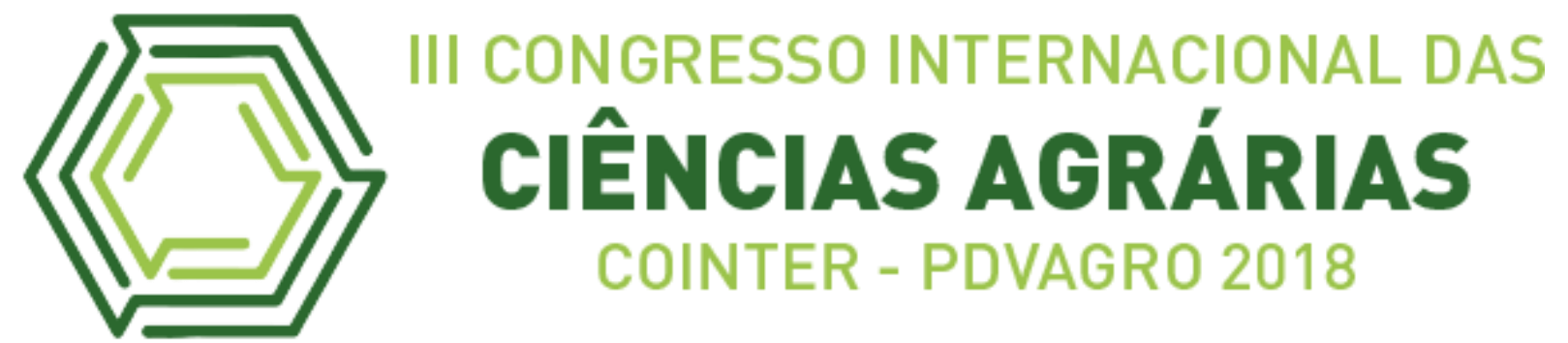

\title{
CARACTERIZAÇÃO FÍSICO-QUÍMICA DE FRUTOS DE MAXIXE DO REINO
}

\section{PHYSICO-CHEMICAL CHARACTERIZATION OF MAXIXE OF THE KINGDOM Apresentação: Pôster}

\begin{abstract}
Mariana Costa Rampazzo ${ }^{1}$; Fabrício Vieira Dutra ${ }^{1}$; Rita de Cássia Santos Nunes²; Gabriela Leite Silva ${ }^{3}$; Adriana Dias Cardoso ${ }^{4}$
\end{abstract}

\section{DOI: https://doi.org/10.31692/2526-7701.IIICOINTERPDVAGRO.2018.00371}

\section{Introdução}

\section{Introdução}

O maxixe do reino (Cyclanthera pedata L.), também conhecido como maxixe paulista ou maxixe peruano, proveniente do cruzamento Cucumis anguria com o Cucumis longipes, é uma hortaliça de fácil crescimento, rústica, resistente às pragas e doenças, requer poucos tratos fitossanitários e culturais, e apresenta prolongado período de frutificação, podendo ser encontrada no Brasil, Bolívia, Chile, Colômbia, Argentina e no Peru. No território Brasileiro, no entanto, área de produção ocorre nas áreas de maior influência da cultura africana, ou seja, Regiões Norte, Nordeste e Sudeste (NASCIMENTO et al., 2011).

A planta se assemelha à do pepino, porém apresenta porte menor, seu fruto é globularalongado, liso, quando imaturo é tenro, e em ponto de consumo, é esbranquiçado. Sua produção é tipicamente em clima quente, suportando temperatura e pluviosidade elevadas, inclusive durante o verão. Baixas temperaturas prejudicam todas as fases da cultura (PEPATO et al., 2011).

Segundo Gonçalves et al., (2009) as características físicas e químicas do fruto como tamanho, massa volume, firmeza, relação de açúcares redutores, teores de ácidos orgânicos e compostos fenólicos são muito importantes pois através dessas análises que é possível determinar o ponto ideal dos frutos exercendo também influência direta sobre a vida útil dos

\footnotetext{
1 Mestrando (a) em Agronomia, Universidade Estadual do Sudoeste da Bahia, anairam.rampazzo@gmail.com;fabriciovieira94@hotmail.com

2 Engenheira Agrônoma, Universidade Estadual do Sudoeste da Bahia, nunes.rcs@gmail.com

${ }^{3}$ Graduanda em Agronomia, Universidade Estadual do Sudoeste da Bahia, gabriela.leitesilva@hotmail.com

${ }^{4}$ D.Sc., pesquisadora PNPD/CAPES/UESB, email: adriuesb@yahoo.com.br
} 
mesmo. No entanto, na literatura não se encontra trabalhos de pós-colheita com maxixe do reino, sendo de extrema importância que haja estudos dessa hortaliça.

Dessa maneira, o objetivo do presente trabalho foi verificar as características físicoquímicas de frutos de maxixe do reino comercializados em Vitória da Conquista, Bahi

\section{Fundamentação Teórica}

As hortaliças possuem grande importância na alimentação humana, pois entre os alimentos de origem vegetal, esta possui um considerável valor nutritivo. Dentre essas, o maxixe do reino, pertencente à família Cucurbitaceae, é fonte de minerais (cálcio, fósforo, ferro, magnésio e zinco), vitaminas (vitamina $\mathrm{C}$ e do complexo B) e fornecem poucas calorias. No entanto, são escassos estudos sobre as características agronômicas e químicas dessa curcubitácea (BENEVIDES et al.,2013).

Os alimentos de origem vegetal apresentam particularidades devido à sua composição química. Devido ao conteúdo de ácido orgânicos, os valores de $\mathrm{pH}$ em hortaliças variam de 2,0 a 5,0. Além deste ácido, tem forte influência sobre o $\mathrm{pH}$, a quantidade elevada de carboidratos como a glicose, frutose várias pentoses e pectinas. E essa propriedade química constituem um ambiente favorável ao desenvolvimento de microorganismos, que alguns destes são deteriorantes, responsáveis por parte das perdas pós-colheita (FEITOSA et al.,2009).

O período de maturação dos frutos, está diretamente relacionado às alterações químicas que ocorrem nos mesmo, como a perda da firmeza devido à quebra enzimática da parede celular, a hidrólise do amido e de outras macromoléculas, alteração na relação dos açúcares, redução nos teores de ácidos orgânicos e compostos fenólicos. Também se observa degradação de clorofila e acúmulo de outros pigmentos, como carotenoides e antocianina, nas células da epiderme dos frutos, que estão associados à diminuição da qualidade. A clorofila pode ser degradada em compostos castanhos acinzentados indesejáveis tais como a feoforbida e feofitina, que posteriormente pode ser metabolizado em compostos incolores (SILVA et al.,2016).

Conforme Silva (2014), as características como peso comprimento, largura e espessura de um fruto refletem na aceitabilidade do produto pelo consumidor e no rendimento industrial, enquanto os teores de sólidos solúveis, acidez titulável, balanço sólidos solúveis/acidez (SST/AT), são indicadoras das características organolépticas, importantes tanto na industrialização como no consumo de frutas in natura. 
De uma maneira geral, a caracterização física e físico-química de frutos é determinada também pela influência das condições edafoclimáticas, dos tratos culturais, época de colheita, em que as características físicas dos frutos tem grande importância quando se refere à determinação da variabilidade genética de uma espécie que pode subsidiar programas de melhoramento genético, bem como sua relação com os fatores ambientais (NASCIMENTO et al.,2014).

\section{Metodologia}

O experimento foi conduzido no Laboratório de Melhoramento e Produção Vegetal, da Universidade Estadual do Sudoeste da Bahia, campus Vitória da Conquista - BA, em setembro de 2018.

Os frutos de maxixe do reino foram provenientes do Centro Econômico de Abastecimento Sociedade Anônima (CEASA), no município de Vitória da Conquista e encaminhados para analise ao Laboratório de Melhoramento e Produção Vegetal.

As amostras foram constituídas de dois frutos, com 9 repetições, totalizando 18 frutos. As características avaliadas foram: a) Massa do fruto: a partir da pesagem de cada fruto utilizando balança com precisão de $0,001 \mathrm{~g}$; b) comprimento do fruto: medido com o auxílio de uma régua milimetrada $(\mathrm{mm})$; c) número de sementes/fruto: determinado por contagem manual; d) Textura do fruto: medida nos frutos in natura utilizando-se Texturômetro Stevens - LFRA Texture Analyser, com a ponta de prova-TA 9/1000 tomando-se duas leituras na região longitudinal, em ambos os lados de uma mesmo fruto. Os resultados foram expressos em N. e) Sólidos solúveis: determinado pelo método da AOAC (1992) em amostras de frutos in natura, utilizando-se um refratômetro manual. Os frutos foram triturados com $10 \mathrm{~mL}$ de água destilada, transferindo- se o suco celular para o prisma do refratômetro. Os resultados foram expressos em ${ }^{\circ}$ Brix. f) pH dos frutos: determinado pelo método da AOAC (1992), em amostras de frutos in natura, utilizando-se pHmetro Marte, modelo MB-10. g) acidez total titulável (\% de ácido cítrico.100g-1 de polpa): determinada por meio de titulação com solução de $\mathrm{NaOH} 0,1 \mathrm{~N}$ e indicador fenolftaleína, de acordo com o Instituto Adolfo Lutz (1985).

Os dados submetidos a análise descritiva determinando a média, o valor mínimo e máximo, o desvio padrão e o coeficiente de variação, utilizado o programa Microsoft Office Excel 2010. 


\section{Resultados e Discussões}

Observa-se que a média e o desvio padrão para comprimento, número de sementes e massa do fruto de maxixe do reino foram 15,68 $\pm 3,69 \mathrm{~mm}, 14,78 \pm 2,10$ e 88,07 $\pm 38,20 \mathrm{mg}$, respectivamente (tabela1). Diferente dos resultados encontrados por Porto (2016), em trabalho com estádios de maturação de maxixe do reino no Norte de Minas Gerais, o qual obteve para comprimento médio dos frutos $12,75( \pm 2,32) \mathrm{mm}$ e $51,70 \mathrm{mg}( \pm 25,43)$ para massa média do fruto.

Conforme Assis et al. (2015), essas características estão associadas à variabilidade da espécie e as condições edafoclimáticas em que está se encontra, podendo fornecer informações para o estabelecimento das plantas.

Tabela 1. Valores máximo, mínimo, média, mediana, variância, desvio padrão e coeficiente de variação das características comprimento, número de sementes e massa do fruto de maxixe do reino. Vitória da Conquista, Ba, 2018.

\begin{tabular}{lccc}
\hline Características & Comprimento & $\mathrm{N}^{\mathbf{0}}$ de sementes & Massa do fruto \\
\hline Mínimo & 8,40 & 11,00 & 31,16 \\
Máximo & 20,70 & 19,00 & 155,78 \\
Média & 15,68 & 14,78 & 88,07 \\
Mediana & 16,68 & 15,00 & 98,66 \\
Variância & 13,62 & 4,42 & 1459,27 \\
Desvio Padrão & 3,69 & 2,10 & 38,20 \\
Coeficiente de variação (\%) & 23,54 & 14,22 & 43,38 \\
\hline
\end{tabular}

Para a textura, $\mathrm{pH}$, sólidos solúveis e Acidez titulável dos frutos a média encontrada foi $28,29( \pm 8,79) \mathrm{N}, 6,14( \pm 0,11), 1,70( \pm 0,30)^{\circ}$ Brix e $0,72( \pm 0,19) \mathrm{g} / 100 \mathrm{~g}$ de ácido cítrico respectivamente. Os valores não se assemelham aos encontrado por Silveira et al. (2015), para espécie Cucumis anguria, onde o valor médio de $\mathrm{pH}$ foi 5,1, sólidos solúveis 3,34 Brix e acidez titulável 3,3 g/100g de ácido cítrico.

Segundo os mesmos autores a diminuição da acidez e o aumento do pH, são característicos da fase de senescência dos frutos e decorrentes do metabolismo de ácidos orgânicos, juntamente com os sólidos solúveis que representam os ácidos, os sais, as vitaminas, os aminoácidos, algumas pectinas e os açúcares presentes nos vegetais, são comumente utilizados como índice dos açúcares totais, indicando o grau de maturidade. 
A firmeza de um fruto, também está associado a maturação do mesmo, pois dá uma idéia das transformações na estrutura celular, coesão das células e alterações bioquímicas, responsáveis pela textura do produto (BOTTEGA et al.,2014).

Tabela 2. Valores máximo, mínimo, média, mediana, variância, desvio padrão e coeficiente de variação da Textura, $\mathrm{pH}$, sólidos solúveis e Acidez titulável dos frutos de maxixe do reino. Vitória da Conquista, Ba, 2018.

\begin{tabular}{lcccc}
\hline Características & Textura & $\mathrm{pH}$ & Sólidos solúveis & Acidez titulável \\
\hline Mínimo & 16,50 & 5,93 & 1,30 & 0,50 \\
Máximo & 45,06 & 6,31 & 2,00 & 1,20 \\
Média & 28,29 & 6,14 & 1,70 & 0,72 \\
Mediana & 26,24 & 6,12 & 1,90 & 0,70 \\
Variância & 76,31 & 0,01 & 0,09 & 0,04 \\
Desvio Padrão & 8,74 & 0,11 & 0,30 & 0,19 \\
Coeficiente de variação $(\%)$ & 30,88 & 1,83 & 1765 & 27,50 \\
\hline
\end{tabular}

\section{Conclusão}

Os frutos de maxixe do reino comercializados no Ceasa de vitória da Conquista- BA possui maturidade ideal para consumo.

\section{Referências}

AOAC - Association of Official Analytical Chemists - Official Methods of Analysis of the AOAC. 10.ed. Washington, 1992. 1115 p.

ASSIS, J.P.; SOUSA, R.P.; LINHARES, P.C.F.; PEREIRA, M.F.S.; MOREIRA, J.C. Avaliação biométrica de caracteres do melão de São Caetano (Momordica charantia L). Revista Brasileira de Plantas Medicinais, v.17, n.4, p.505-514, 2015.

BENEVIDES, C.M. de J.; SOUZA, R.D.B.; SOUZA, M.V. de; LOPES, M.V. Efeito do processamento sobre os teores de oxalato e tanino em maxixe (Cucumis anguria L.), jiló (Solanum gilo), feijão verde (Vigna unguiculata (L.) Walp.) e feijão-andu (Cajanus cajan (L.) Mill sp.). Alimentos e Nutrição, v.24, n.3 p.321-327, 2013.

BOTTEGA,S.P.; RECH, J.; TANAKA , K. S.; BORELLI , A. B.; GORDIN, C. R. B.; SCALON, S. P. Q. Diferentes cortes e embalagens no processamento mínimo de chuchu. Cultivando o Saber, v. 7, n. 4, p. 312 - 322, 2014. 
FEITOSA, T.; GARRUTI, D. S.; SILVA, Q. C. R.; LIMA, R. J.; BEZERRA, F. M. L.; AQUINO, B. F.; SANTOS, A.B. Qualidade de frutos de melancia produzidos com reuso de água de esgoto doméstico tratado. Revista Tecnológica, v. 30, n. 1, p. 53-60, 2009.

GONÇALVES, V. D.; MÜLLER, D. L.; FERREIRA, F.; CAMILI, E. C. Maturação fisiológica de sementes de pimenta. Revista Caatinga, Mossoró, v. 28, n. 3, p. 137-146, 2015.

INSTITUTO ADOLFO LUTZ. Métodos químicos e físicos para análise de alimentos. 3.ed. São Paulo: Normas analíticas do Instituto Adolfo Lutz, 1985. v. 1 ,553p.

NASCIMENTO A. M. C. B.; NUNES R. G. F. L.; NUNES, L. A. P. L. Elaboração e avaliação química, biológica e sensorial de conserva de maxixe (Cucumis anguria L.). Revista ACTA Tecnológica, v.6, n.1, p.123-136, 2011.

NASCIMENTO, R. S. M.; CARDOSO, J. A.; COCOZZA, F. D. M. Caracterização física e físico-química de frutos de mangabeira (Hancornia speciosa Gomes) no oeste da Bahia. Revista Brasileira de Engenharia Agrícola e Ambiental, v.18, n.8, p.856-860, 2014. PEPATO, H.; SILVESTRE, F.M.; BRUGNARO, C.; SALA, F.C. Avaliação de produção de maxixe paulista. Horticultura Brasileira, v.29, n. 2, p. 2338-2342,2011.

SILVA, F.C. Crescimento e alterações fisiológicas pós-colheita em frutos de maxixe (Cucumis anguria). Tese (doutorado) - Universidade Federal de Viçosa, 78 f.,Viçosa, MG, 2016.

SILVA, K. C. R. Análise Físico-Química da melancia (Citrullus lanatus) na forma in natura do município de Buritis-Ro. Monografia (graduação em Licenciatura em Química) Faculdade de Educação e Meio Ambiente - FAEMA, Ariquemes-Ro,32 f.,2014.

SILVEIRA, P. T. S.; SILVA, N. M. C.; REIS, M. F. T.; LANDIM, L. B; AQUINO, A. A. Qualidade pós-colheita do maxixe (Cucumis Anguria L.) revestido com amido de milho adicionado do extrato de própolis. Revista Brasileira de Tecnologia Agroindustrial, v. 9, n.2: p. 1888-1899, 2015. 